\title{
Bronchodilator Delivery During Simulated Pediatric Noninvasive Ventilation
}

\author{
Cynthia C White MSc RRT-NPS FAARC, Dave N Crotwell RRT-NPS FAARC, \\ Shuijie Shen PhD, John Salyer RRT-NPS MBA FAARC, Delphine Yung MD, \\ Jiang Zheng PhD, and Robert M DiBlasi RRT-NPS FAARC
}

\begin{abstract}
BACKGROUND: Noninvasive ventilation (NIV) is usually applied using bi-level positive airway pressure devices, and many of these devices use a single-limb patient circuit with an integrated leak port to purge the circuit of exhaled carbon dioxide. Sometimes bronchodilator therapy is indicated in pediatric patients, but there have been no studies of the optimal nebulizer position, with respect to leak, during pediatric NIV. We hypothesized that there would be no differences in albuterol delivery with a vibrating-mesh nebulizer between 3 different positions/exhalation leak valve combinations in the patient circuit during simulated pediatric NIV. METHODS: A simulated upper airway model was attached to a lung model that simulated spontaneous breathing. A noninvasive ventilator equipped with heated wire circuit and heated humidifier was attached to the lung model via a pediatric oronasal mask. Albuterol $(5 \mathrm{mg})$ was delivered with a vibrating-mesh nebulizer, at 3 different circuit position/leak condition combinations: prior to the humidifier and leak valve; between the humidifier and leak valve; and integrated within the mask and after the leak. Albuterol was captured on a filter and quantified with chromatography. RESULTS: Greater albuterol mass was delivered to the filter with the nebulizer integrated into the mask than at any other testing condition $(P<.001)$. In the conditions where the nebulizer was placed prior to the exhalation leak valve, greater drug delivery was observed when the nebulizer was placed proximal to the mask (position 2) than when placed prior to the humidifier (position $3, P=.002$ ). CONCLUSIONS: Albuterol delivery during simulated pediatric NIV was affected by the position of the nebulizer in relation to the expiratory leak valve and the nebulizer's distance from the filter. A vibrating-mesh nebulizer placed intra-mask may provide a better alternative for medication delivery than those previously used during pediatric NIV. Key words: noninvasive; ventilation; NIV; bronchodilator; pediatric; nebulizer; albuterol; vibrating mesh; nebulizer. [Respir Care 2013;58(9):1459-1466. () 2013 Daedalus Enterprises]
\end{abstract}

\section{Introduction}

Noninvasive ventilation (NIV) is increasingly used as an alternative to invasive ventilation in pediatric patients,

\footnotetext{
Ms White is affiliated with the Respiratory Care Division, Cincinnati Children's Hospital, Cincinnati, Ohio. Mr Crotwell, Mr Salyer, Dr Yung, and Mr DiBlasi are affiliated with Seattle Children's Hospital, Seattle, Washington. Dr Shen and Mr DiBlasi are affiliated with Seattle Children's Hospital Research Institute, Seattle, Washington. Dr Zheng is affiliated with Division of Gastroenterology and Hepatology, Department of Pediatrics, University of Washington School of Medicine, and Seattle Children's Research Institute, Seattle, Washington.
}

This study was partly supported by Tri-Anim, which provided the NIVO nebulizers. The authors have disclosed no other conflicts of interest. including those with asthma. NIV provides relief from airway obstruction in children by physically stenting airways open during the respiratory cycle, reduces work of breathing and intrinsic PEEP, and increases alveolar ven-

\footnotetext{
Ms White presented a version of this paper at the OPEN FORUM of the 58th AARC Congress, held November 10-13, 2012, in New Orleans, Louisiana.

Correspondence: Cynthia C White MSc RRT-NPS FAARC, Cincinnati Children's Medical Center, Division of Respiratory Care, MLC \#5032, 3333 Burnett Avenue, Cincinnati, OH 43669, cynthia.white@cchmc.org
}

DOI: $10.4187 /$ respcare.02171 


\section{Bronchodilator Delivery During Simulated Pediatric Noninvasive Ventilation}

tilation. Obvious benefits include ability of the patient to communicate, lack of a high resistance artificial airway, decreased bronchial irritation and need for sedation, and elimination of ventilator-acquired pneumonia risk. ${ }^{1}$ NIV is associated with improved mortality in adult patients with COPD and other forms of respiratory distress. ${ }^{2-12}$ One randomized controlled trial ${ }^{13}$ and several small observational studies ${ }^{14-16}$ found NIV safe and effective in supporting children with respiratory failure, including patients with asthma not responding to conventional therapies.

$\mathrm{Bi}$-level positive airway pressure (BPAP) is a common NIV mode in the pediatric ICU. Many BPAP devices use a single-limb patient circuit with an integrated fixed-leak port "expiratory valve" and high flows to purge the circuit of exhaled carbon dioxide. A major concern with administering aerosolized drugs in this system is whether the combination of high system flow and leak delivers any aerosolized drug to the patient. Additionally, factors influencing the aerosol delivery during NIV include type of ventilator; ventilation mode; circuit humidity; type of interface; type and configuration of aerosol generator; drug-related factors such as aerosol particle size; breathing parameters; and patient-related factors such as level of respiratory distress, hemodynamic status, type and severity of lung disease, and synchronization of aerosol generation with inspiratory air flow. ${ }^{17}$ Also, the ability to tolerate a face mask, the quality of mask fit, the degree of leak around the mask, and the position of the exhalation leak valve in the NIV circuitry all may impact drug delivery.

Until recently, nebulizer and leak valve position in the circuit could not be moved, for technical reasons. New developments include face masks with interchangeable leak adapters; vibrating-mesh nebulizers, which add no flow to the circuit; and the very recent introduction of a lightweight vibrating-mesh nebulizer that can be integrated proximal to a pediatric oronasal mask. These all allow variations to the standard NIV circuit setup. We tested the null hypothesis that there would be no difference in albuterol delivery between a standard vibrating-mesh nebulizer placed before the humidifier and before the leak, after the humidifier and before the leak, and an integrated mask vibrating-mesh nebulizer placed after the leak.

\section{Methods}

This study was designed and performed, and the data were analyzed in the Respiratory Therapy Department of Seattle Children's Hospital, Seattle, Washington, under the direct supervision of the senior author (RMD). The first author (CCW) was present for the study design, acquiring data, analyzing data, and the entire process of writing the paper. NIVO aerosol devices were donated by Tri-Anim, Valencia, California, and laboratory supplies were purchased with funds from a research grant provided

\section{QUICK LOOK}

\section{Current knowledge}

Delivery of nebulized bronchodilator during noninvasive ventilation is common in adults. The optimum nebulizer position in the noninvasive ventilation circuit in pediatric subjects has not been determined.

\section{What this paper contributes to our knowledge}

In a model, delivery of albuterol from a mesh nebulizer was significantly impacted by the nebulizer's circuit position, as it related to fixed leak in a single limb circuit. Aerosol delivery was greatest when the nebulizer was integrated into the mask, between the leak and the patient.

by the Center for Developmental Therapeutics, Seattle Children's Research Institute, Seattle, Washington.

\section{Pediatric Upper Airway and Lung Model}

Our pediatric upper airway and lung model consisted of a pediatric resuscitation manikin (Little Junior, Laerdal Medical, Stavanger, Norway), a $5.5 \mathrm{~mm}$ inner diameter endotracheal tube, and a lung model (ASL 5000, Ingmar Medical, Pittsburgh, Pennsylvania) set to simulate a child with severe status asthmaticus ${ }^{18,19}$ : compliance $20 \mathrm{~mL} /$ $\mathrm{cm} \mathrm{H}_{2} \mathrm{O}$, resistance $15 \mathrm{~cm} \mathrm{H}_{2} \mathrm{O} / \mathrm{L} / \mathrm{s}$, breathing frequency 30 breaths/min, and inspiratory muscle pressure adjusted to obtain a tidal volume of $180 \mathrm{~mL}$ during NIV. The test lung was also configured to mimic active exhalation by setting the expiratory muscle pressure to $5 \mathrm{~cm} \mathrm{H}_{2} \mathrm{O}$. Two bacterial/viral electret filters (Respirgard-II, Vital Signs, Englewood, Colorado) were connected in series between the endotracheal tube and the lung model. One filter captured the inspired drug, and the second filter protected the internal components of the lung model (Fig. 1).

\section{Ventilator and Humidification}

The ventilator (V60, Philips Respironics, Murrysville, Pennsylvania) was attached to a heated wire circuit (850, Fisher \& Paykel, Auckland, New Zealand), the expiratory leak-valve, a face mask, and resuscitation manikin. The ventilator settings were BiPAP S/T mode, inspiratory pressure $16 \mathrm{~cm} \mathrm{H}_{2} \mathrm{O}$, expiratory pressure $8 \mathrm{~cm} \mathrm{H}_{2} \mathrm{O}, \mathrm{F}_{\mathrm{IO}_{2}} 0.50$, rise time setting 2, and Autotrak trigger. The oronasal mask (size small AF531, Philips Respironics, Murrysville, Pennsylvania) with interchangeable "fixed orifice" leak port elbow adapters was firmly secured to the manikin face. The tidal volume $(\sim 180 \mathrm{~mL})$ was confirmed prior to 


\section{Bronchodilator Delivery During Simulated Pediatric Noninvasive Ventilation}

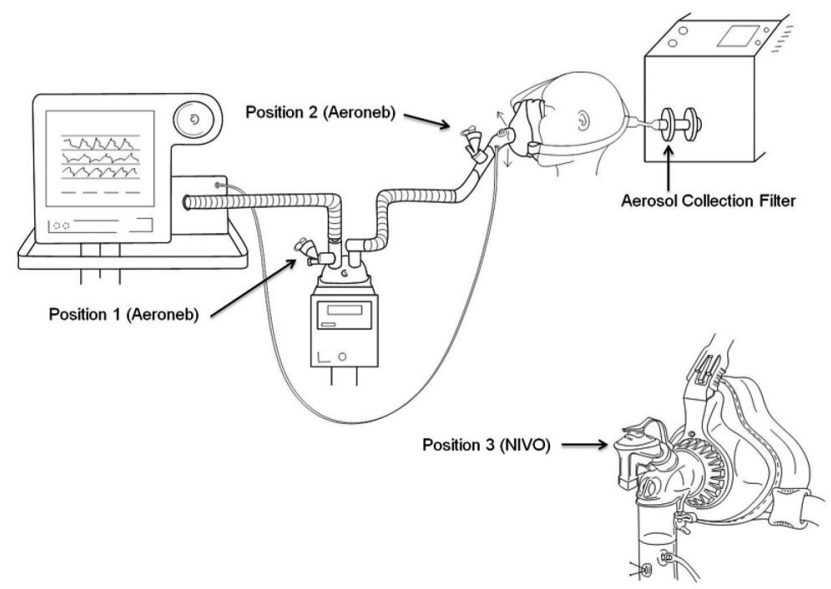

Fig. 1. Experimental setup.

and during all testing, to assure an adequate mask seal. The circuit and system was heated to approximately $35^{\circ} \mathrm{C}$, and the lung model was warmed to $37^{\circ} \mathrm{C}$ for 20 min prior to testing. These temperatures were maintained throughout the study.

\section{Nebulizers}

Two models of vibrating-mesh nebulizer (Aeroneb Solo, Aerogen, Mountain View, California; and NIVO, Philips Respironics, Murrysville, Pennsylvania) were used. Both nebulizers can be placed in-line during NIV. The NIVO is designed specifically for NIV, and attaches to an adapter in the face mask (Fig. 2). All the nebulizers were powered with a nebulizer controller (Pro-X, Aerogen, Mountain View, California).

Vibrating-mesh nebulizers are highly efficient, ${ }^{20}$ providing 2-4 times greater drug delivery than jet nebulizers during pediatric mechanical ventilation. ${ }^{21}$ They also allow medication to be delivered without having to disconnect the patient from positive pressure, can remain in-line when not being used, and some models can be configured to provide continuous bronchodilator therapy. Unlike a jet nebulizer, no flow is added to the patient circuit by a vibrating-mesh nebulizer. Avoiding the addition of extra flow into the circuit may prevent patient-ventilator dyssynchrony from ineffective triggering that often occurs in small pediatric patients or hyperinflated asthmatic patients with intrinsic PEEP.

\section{Nebulizer Positions}

In position 1 (pre-humidifier, pre-leak) the Aeroneb Solo was placed on the dry side of the heated humidifier, and a \#2 standard leak adapter elbow (Philips Respironics, Murrysville, Pennsylvania) was attached to the face mask. In position 2 (post-humidifier, pre-leak) the Aeroneb Solo

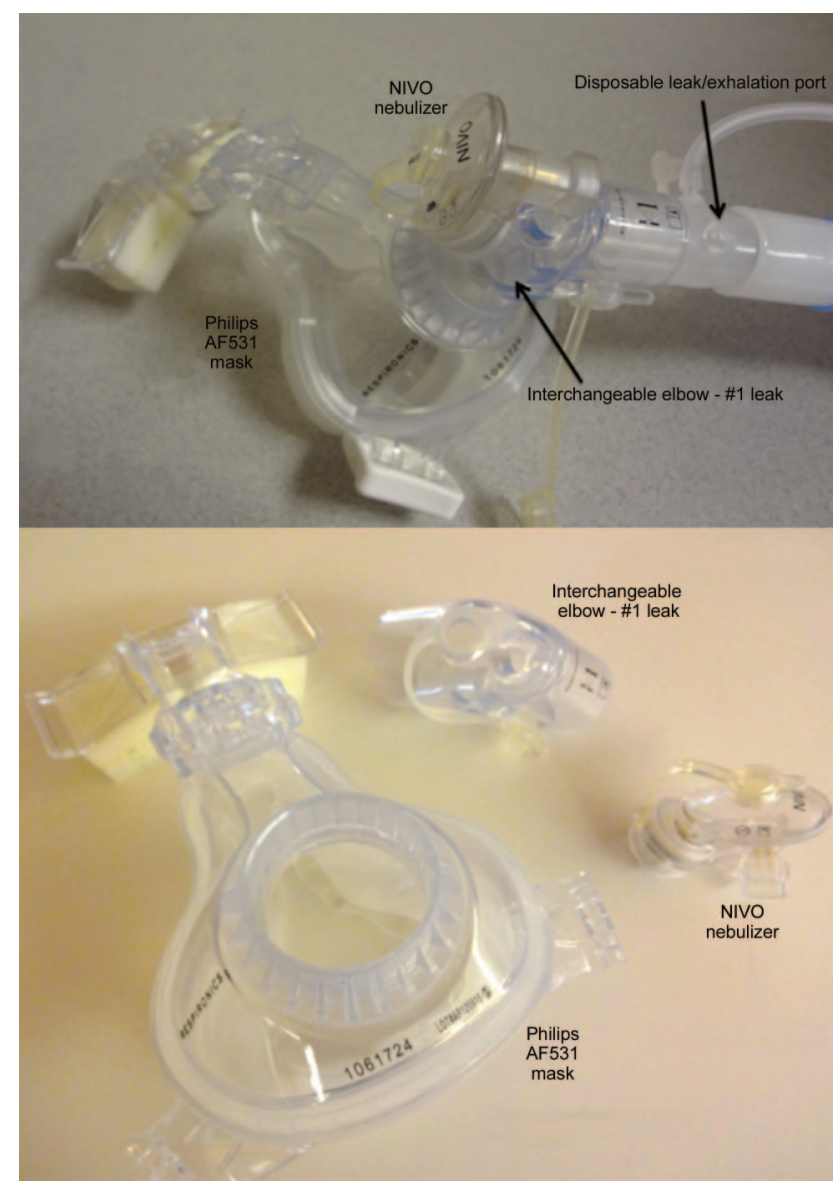

Fig. 2. Above: AF531 mask with interchangeable elbow and NIVO nebulizer assembled and (below) disassembled.

was placed after the heated humidifier and just prior to the \#2 standard leak adapter elbow and face mask. In position 3 (post-leak, intra-mask) the NIVO nebulizer was attached to the mask using a \#1 standard leak NIVO entrainment elbow ( $0 \%$ leak), and the \#2 standard leak entrainment elbow was removed and replaced with a standard disposable exhalation valve (DEP, Philips Respironics, Murrysville, Pennsylvania).

Continuous expiratory leak was observed with the V60 ventilator with the proximal pressure line (no data). Calculated leak rates during the testing were similar between the standard disposable exhalation valve and the standard \#2 leak entrainment elbow.

\section{Medication Delivery}

The nebulizers were placed into each of the 3 respective positions, and the system heat and humidification was allowed to stabilize prior to testing at each condition. Albuterol $(5 \mathrm{mg})$ was drawn up with a $1 \mathrm{~mL}$ pipette and mixed with $2.5 \mathrm{~mL}$ of normal saline for a total solution volume of $3.5 \mathrm{~mL}$, placed into the nebulizer, and nebulized into 


\section{Bronchodilator Delivery During Simulated Pediatric Noninvasive Ventilation}

the circuit. Three doses of albuterol were given in each of 3 nebulizers tested at each of the circuit positions ( 9 measurements at each location, 27 total measurements). Testing was completed when all of the solution was nebulized. The bacterial/viral electret filter at the end of the endotracheal tube was removed, labeled, and recorded in a laboratory notebook, and placed in a refrigerator. The manikin face was dried between each change of nebulizer position, and fluid accumulation in the manikin upper airway was eliminated to reduce the likelihood of large drug particles reaching the filter. The mask was secured to eliminate any system leaks, based on tidal volume delivery $(180 \mathrm{~mL})$ to the lung model and calculated leak. All data regarding lung model triggering, volume, pressure, flow, and waveform analysis were sampled at $500 \mathrm{~Hz}$ and stored in the lung model's software (version 3.2). These data were later analyzed to determine whether nebulizer performance and condensation affected triggering.

\section{Albuterol Measurement}

Albuterol was recovered from the bacterial/viral electret filter quantified using High-Performance Liquid Chromatography (HPLC). The filters were eluted with $20 \mathrm{~mL}$ methanol, shaken, and thoroughly withdrawn under negative pressure. The elution liquid was collected in $50 \mathrm{~mL}$ centrifuge tubes. The samples were dried with nitrogen gas flow. The residue was reconstituted by adding $200 \mu \mathrm{L}$ of acetonitrile/water (1:1) to each sample. The samples were analyzed via HPLC (Agilent 1100 system, Agilent, Santa Clara, California) with ultraviolet detection, a quaternary pump, diode array detector, and precolumn $(\mathrm{C} 18,2 \mu \mathrm{m})$ and analytical columns (XDB-C8, $46 \times 150 \mathrm{~mm}, 5 \mu \mathrm{m}$ ). The mobile phase was methanol $20 \mathrm{mM}$ potassium phosphate buffer ( $\mathrm{pH} 3.0)(5: 95)$, and the flow rate was $1 \mathrm{~mL} /$ min. The detector wavelength was set at $278 \mathrm{~nm}$. Twenty microliters of each sample was injected into the HPLC system. The retention time was $16.5 \mathrm{~min}$. The residual albuterol in the filters was quantified by a standard curve range from $0.25 \mathrm{mg} / \mathrm{mL}$ to $3.0 \mathrm{mg} / \mathrm{mL}$ Albuterol recovery was measured with a known concentration prior to the experiment, and approximately $100 \%$ of the nominal dose of albuterol was recovered from the filter.

\section{Statistical Analysis}

The albuterol concentrations were recorded in spreadsheet software (Excel, Microsoft, Redmond, Washington). The data are expressed as mean \pm SD or percent of nominal dose placed into the nebulizer. Statistical analyses were performed in statistics software (SPSS 20, SPSS, Chicago, Illinois). One-way analysis of variance was used, with the Tukey test for post hoc analysis to compare differences between the mean delivered albuterol mass at the

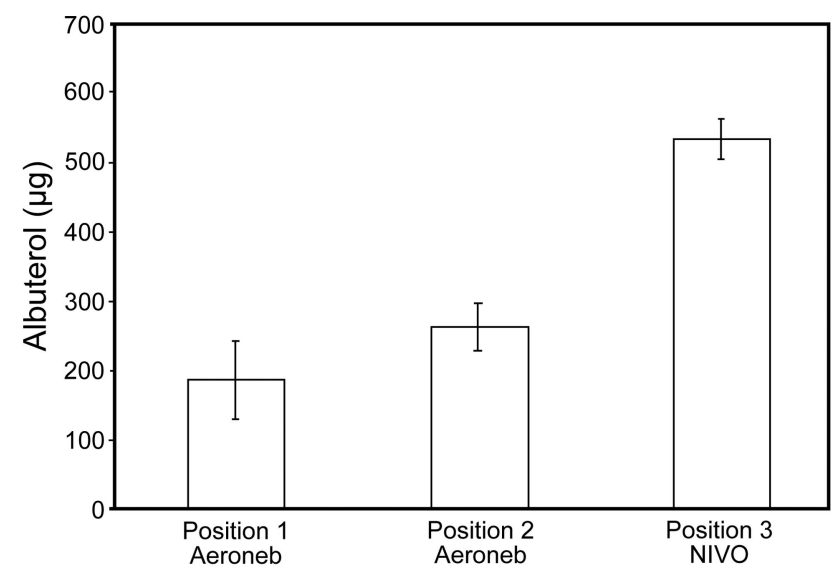

Fig. 3. Delivered albuterol mass. All the experiments were conducted using $5 \mathrm{mg}$ albuterol. The values represented are mean \pm SD albuterol delivered to the filter in 3 runs per nebulizer, at 3 locations. All the differences are significant.

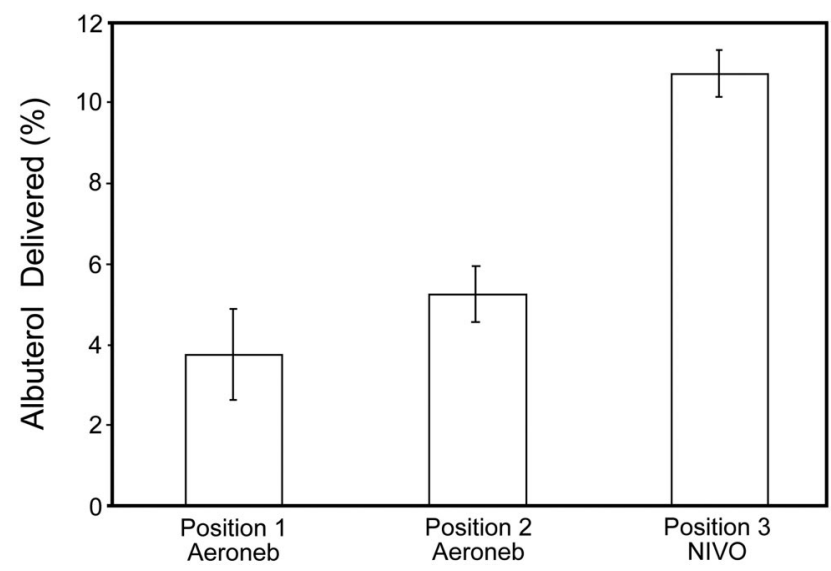

Fig. 4. Delivered albuterol expressed as a percentage of nominal dose. All the experiments were conducted using $5 \mathrm{mg}$ albuterol. The values represented are percentage of the nominal dose $(5 \mathrm{mg}$ albuterol) in 3 runs per nebulizer, at 3 locations.

3 circuit position/leak conditions. Statistical significance was set a priori at $P<.05$.

\section{Results}

Albuterol delivered to each filter is expressed in absolute values (Fig. 3) and as a percentage of the nominal dose (5 mg albuterol, Fig. 4) at each position. There was greater albuterol delivery with the NIVO vibrating-mesh nebulizer placed at the mask (position 3 ) than with the other 2 testing conditions $(P<.001)$. With the Aeroneb Solo nebulizer, delivery was greater when the nebulizer was between the leak valve and the humidifier (position 2) than when the nebulizer was between the ventilator and humidifier (position 1) $(P=.002)$. 


\section{Bronchodilator Delivery During Simulated Pediatric Noninvasive Ventilation}

With the nebulizer in position 3, a large amount of albuterol was emitted from the exhalation port during inspiration; this did not occur during the other 2 testing conditions (see Fig. 4). All the breaths were triggered by the lung model. Nebulizer operation caused no differences in delivered inspiratory pressure, tidal volume, or PEEP.

\section{Discussion}

Over the last decade, technologic improvements in nasal and oronasal mask interfaces have allowed successful application of NIV in pediatric patients with severe respiratory distress of different etiologies. Despite limited experimental data, clinicians implement NIV in children with asthma in the pediatric ICU both as an early intervention and as a "rescue" strategy to prevent endotracheal intubation and invasive ventilation. This practice is guided by very little evidence other than approaches previously described in the adult literature.

Patients with asthma require large amounts of inhaled bronchodilators and systemic steroids administered within a relatively short period of time. Thus, timely and effective delivery of bronchodilator therapy can play an important clinical role in reducing airway obstruction, ventilatory impairment, and respiratory distress. ${ }^{7-9}$ Studies in vitro suggest greater aerosol drug delivery during NIV than when no positive pressure is applied to a lung model. ${ }^{8}$ Studies in children with cystic fibrosis have demonstrated $30 \%$ greater bronchodilator delivery following nebulization provided with NIV than following nebulization without NIV. ${ }^{22}$ Thus, NIV may improve bronchodilator delivery and transiently reduce respiratory distress until other pharmacotherapy has been given time to have a clinical effect.

The major finding of the current study was that albuterol delivery during simulated pediatric NIV is dependent both upon the location of the nebulizer and the location of the fixed expiratory leak in the single-limb BPAP circuit. We observed a $200-300 \%$ greater drug delivery with the NIVO vibrating-mesh nebulizer than with the other 2 commonly used vibrating-mesh nebulizer configurations. We believe these results are related less to the type of vibrating-mesh nebulizer and more to the fact that the nebulizer was placed after the leak valve, which ultimately allowed more drug delivery to the filter and less to the circuit and/or atmosphere.

There have been 3 in vitro studies,23-25 and 2 clinical studies $^{22,26}$ that have evaluated drug delivery during adult NIV. There has been only one pediatric NIV study, and this combined in vitro/in vivo study 22 was designed to evaluate differences in aerosol delivery with and without NIV. Nonetheless, there are very few objective data to guide clinicians when selecting an optimal device or approach for aerosol drug delivery during pediatric NIV. It would be very difficult to extrapolate from the findings of adult NIV aerosol studies and to assume similar results in a pediatric patient. Pediatric patients have smaller tidal volumes, higher breathing frequencies, lower inspiratory/ expiratory ratios, and smaller airway passages than adults. Previous studies have suggested that all of these factors in infants and small children contribute to lower inhaled drug delivery than in adults. ${ }^{27,28}$ In both intubated and nonintubated pediatric patients, aerosol deposition is suggested to be $<1 \%$ of the nominal drug dose, compared to $8-22 \%$ in adults. ${ }^{27}$

We suspect that a major reason why no additional pediatric-specific NIV aerosol studies have recently been described in the literature is due in part to technological limitations of available pediatric nebulizers and NIV mask interfaces. Until very recently, many of the mask interfaces used in this population were prepackaged with the leak exhalation port integrated into the NIV mask, making it physically impossible to place a nebulizer between the leak and the mask during pediatric NIV. Moreover, the weight and awkwardness of placing available aerosol delivery devices in-line may put unnecessary tension on the mask, resulting in greater leak and lower drug delivery to the patient. The lightweight NIVO vibrating-mesh nebulizer represents a suitable new technology that obviates many of the previous concerns related to pediatric drug delivery during NIV.

Adult studies with similar designs have focused on aerosol delivery using novel NIV mask technologies. Branconnier et $\mathrm{al}^{24}$ compared drug delivery during simulated adult NIV using 2 different mask types: one with an integrated mask leak port, and a newer mask version that used a leak elbow that could be adapted to the patient circuit. The latter configuration made it possible for investigators to adapt a jet nebulizer after the leak. Similar to our findings, Branconnier reported greater drug delivery when the jet nebulizer was placed between the leak and the mask. It is interesting to note that the jet nebulizer used by Branconnier et $\mathrm{al}^{24}$ and the vibrating-mesh nebulizer used in the current study, when compared at the respective pre/ post leak conditions, had similar albuterol mass. Despite the smaller tidal volumes, lower transit times for aerosol delivery, and the use of a heated humidifier in our pediatric lung model, we believe that the reason we observed similar findings to the previously described adult lung model study ${ }^{24}$ is because the vibrating-mesh nebulizer may be more efficient than a jet nebulizer. ${ }^{22}$ Thus, we are not surprised to learn that albuterol delivery, expressed per unit of body weight, is much greater during pediatric NIV, comparing data from these 2 studies.

We also chose to use a heated humidifier during this study, whereas most adult NIV studies have not. The application of heated humidity to the patient circuit is an important factor affecting aerosol delivery. Unlike the Branconnier study, we did not test drug delivery without a 


\section{Bronchodilator Delivery During Simulated Pediatric Noninvasive Ventilation}

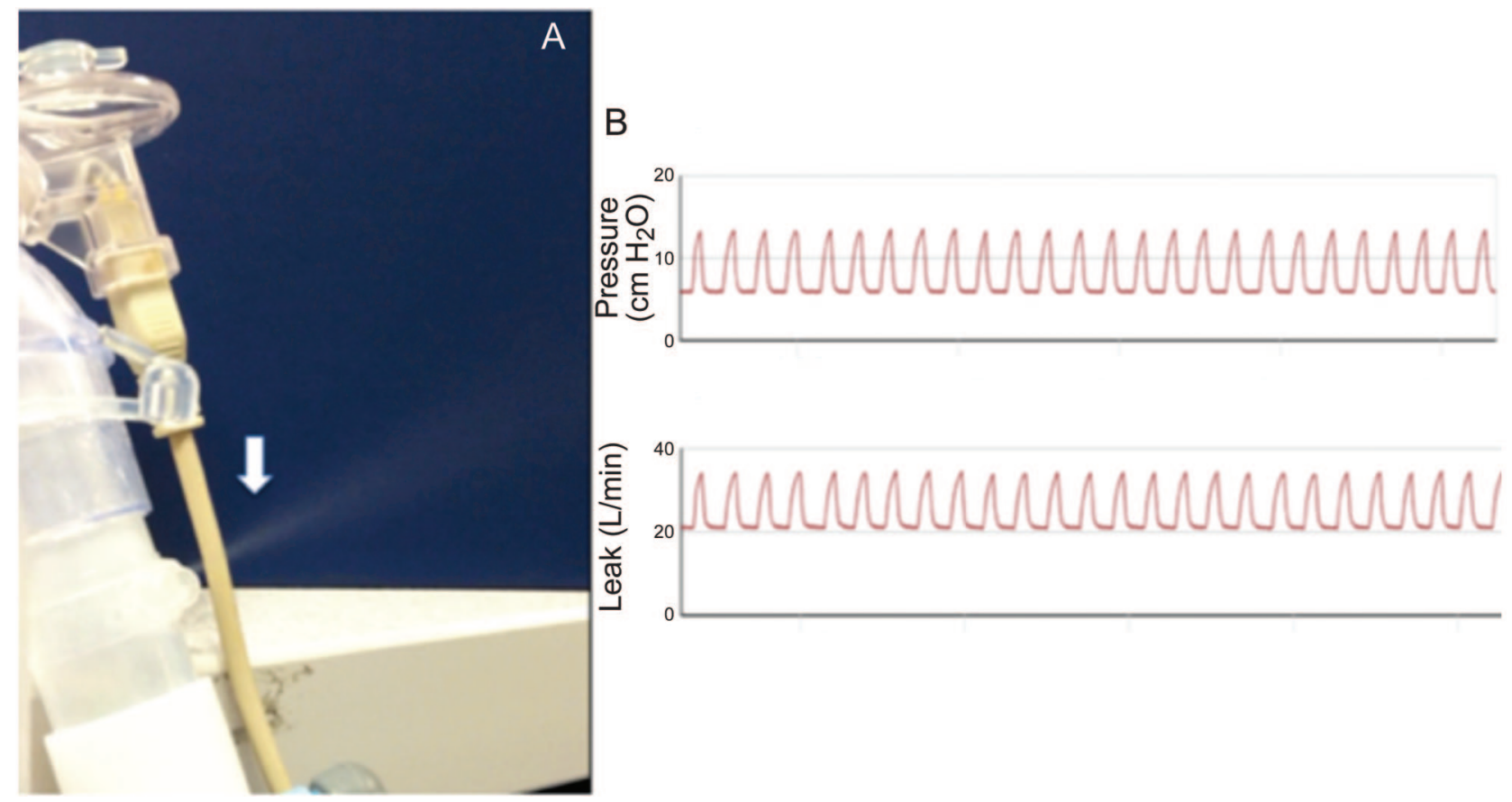

Fig. 5. Effects of inspiratory pressure on leak and aerosol delivery. A: An aerosol plume from the leak port (arrow), with the NIVO nebulizer in position 3, during inhalation suggests that even though the nebulizer is placed after the leak, a substantial amount of drug is lost through the leak port. B: Pressure/time and leak/time scalars from an actual patient receiving bi-level positive airway pressure ventilation from a V60 ventilator. The leak is proportional to the pressure and thus is greatest at peak inspiratory pressure, so a greater proportion of aerosol may be leaving the system during inhalation than during exhalation.

heated humidifier, but, based on a previous study, ${ }^{29}$ aerosolized albuterol delivery is likely to be approximately $200 \%$ greater when humidity is not being applied.

Adding humidification to the NIV circuit may be preferred with asthmatics, due to underlying airway inflammation and high potential for mucus plugging. ${ }^{17}$ Administering high gas flow without humidity may overwhelm the capabilities of the nose and upper airway to properly humidify gas, resulting in drying of airway passages, which may lead to consequent increased nasal resistance and the potential for increased airway reactivity. ${ }^{17}$ As such, high bronchodilator dosages may need to be increased when humidification is added, due to the potential to decrease aerosol delivery by as much as $40-50 \% .^{18}$ These findings also raise the question about whether the heated humidifier should be turned off intermittently or bypassed while aerosolized drugs are being administered during NIV. While this practice cannot be routinely recommended at this time, it should encourage additional research.

Many clinicians from pediatric institutions commonly place nebulizers between the ventilator and the humidifier during all forms of ventilation, including NIV. There is anecdotal evidence that this not only reduces the level of condensation in the circuit, but also results in better drug delivery. In 2 recent reports, Ari and colleagues evaluated bronchodilator delivery during simulated pediatric ${ }^{21}$ and adult ventilation, ${ }^{29}$ using a vibrating-mesh nebulizer at 2 different locations. In this study ${ }^{29}$ there was nearly a $200 \%$ increase in drug delivery when the vibrating-mesh nebulizer was placed between the ventilator and the humidifier during simulated adult ventilation. However, based on the pediatric study ${ }^{21}$ it is unclear whether there were any important differences in aerosol delivery between these 2 positions.

We observed a significant reduction in medication delivery when the vibrating-mesh nebulizer was moved from position 2 or position 3 to position 1 (between the ventilator and humidifier during NIV). There are major and notable differences in the circuit configuration used during NIV and conventional ventilation. The circuits used by Ari et $\mathrm{al}^{21}$ were dual-limb pediatric circuits, and those used in the present study used a BPAP-specific singlecircuit configuration. The gas flow dynamics of a single circuit may be more complex than a dual-limb circuit, because high gas flow coupled with a common inhalation/ exhalation pathway is likely to cause higher turbulence in the system. Thus, we believe that the poor drug delivery observed when the vibrating-mesh nebulizer was placed back at the BPAP ventilator may be multi-factorial. It is likely that the use of high flows may dilute the aerosol bolus being emitted from the nebulizer into the circuit. Also, these high flows may increase the inertial activities of aerosol particles, resulting in drug impaction in the humidifier and along the length of the patient circuit. As 


\section{Bronchodilator Delivery During Simulated Pediatric Noninvasive Ventilation}

such, the beneficial "reservoir-like" effects of the duallimb circuit, observed by Ari et $\mathrm{al}^{21}$ do not readily apply to a single-circuit NIV configuration. This issue is further complicated by the fact that many ventilator companies are now integrating pediatric-specific NIV algorithms into standard ICU ventilators that use a dual-limb circuit. Thus, additional studies are needed to compare medication delivery with all available devices that are being used in the pediatric ICU to provide NIV.

Chatmongkolchart et $\mathrm{al}^{2}$ evaluated medication delivery in an adult lung model using a jet nebulizer and a single circuit BPAP ventilator. Similar to our findings and at comparable peak pressures, they observed a 2 -fold greater increase in drug delivery when the nebulizer was moved away from the BPAP ventilator and placed after the leak port and proximal to the face mask. Calvert et al ${ }^{25}$ nebulized salbutamol with a jet nebulizer at 3 similar positions during simulated adult NIV. Like our study and previous studies, drug delivery was half the value when the nebulizer was placed back at the ventilator, compared with proximal to the patient.

Abdelrahim et al conducted both an in vitro study ${ }^{23}$ and a randomized crossover clinical study ${ }^{26}$ comparing aerosol delivery with a vibrating-mesh nebulizer (Aerogen Pro) to a jet nebulizer at 2 positions within the patient circuit (pre and post leak). Regardless of the nebulizer used, they also observed nearly $200 \%$ greater drug delivery when the nebulizer was placed post-leak. In this study, drug mass was also analyzed coming out of the leak port at both pre and post leak conditions. A greater amount of drug was emitted from the leak port in the pre-leak condition than in the post-leak condition. However, nearly $20 \%$ of the nominal dose of albuterol was recovered from the leak port when the nebulizer was placed after the leak. They state, "For position A (between the leak valve and lung simulator), therefore, all the dose that is aerosolized during the inhalation phase is directed to the inhalation filter."23 While we did not measure aerosol emitted from the leak port during this study, a plume of aerosol (Fig. 5) could be visualized during inhalation, even when the nebulizer was placed after the leak. Also based on Figure 5, the point at which the leak is the greatest using the V60 ventilator is at the peak inspiratory pressure. Thus, it is likely that a large fraction of drug is lost during inhalation. This raises many questions about whether the position of the leak valve in the circuit may influence drug delivery differently during NIV. Future studies need to be conducted to answer this question and determine if placing the leak valve distal to the patient has any effect on carbon dioxide elimination during NIV. We also cannot rule out other confounding variables that may have contributed to differences in drug delivery between the different positions, including different tubing distances or the fact that 2 different types of vibrating-mesh nebulizers were used.
Even though the majority of these in vitro studies pertain to adults, each of the studies used a similar circuit configuration, BPAP ventilator, and in one case ${ }^{23}$ a similar nebulizer to the one used in the current study. Our findings suggest there are differences in drug delivery related to the position of the leak with respect to the leak-port and circuit position that mirror previous observations in aerosol studies using an adult lung model and NIV. Based on these data, clinicians who are not able to place the nebulizer after the leak may benefit more from having it placed just prior to the leak than back at the ventilator.

\section{Limitations}

In this in vitro study we took careful measures to simulate a realistic pediatric clinical environment. This approach was different from those reported in previous NIV aerosol studies. We used modern BPAP ventilators and nebulizers, a heated humidifier, a realistic manikin with oronasal passages, and a heated, actively breathing test lung configured with mechanics values similar to those measured in pediatric asthmatics. However, like all data obtained from aerosol studies in vitro, the results must be approached with some trepidation. The amount of drug delivered to the filter represents the total mass of available drug delivered to the airways, but it does not take into account the amount of respirable drug particles that may be delivered to the peripheral airways of the lungs and where they are needed most. Thus, it is extremely important to mention that, despite making every attempt to avoid large droplets of accumulated liquid medication (combined with humidity) from reaching the filter, it is still possible that this fluid can condense anywhere in the airway model and be delivered to the filter media during inhalation. We also noted that as the nebulizer was placed closer to the simulated patient, there appeared to be more condensation in the mask and circuit. This fluid tended to pool and could not be observed entering the oral or nasal airway openings. Thus is it unlikely, based on the variability of albuterol mass, that large droplets were introduced into the filter.

Additional limitations include using only one particular brand of BPAP ventilator, humidifier, circuit, and mask. We also used one lung model configuration and a single combination of NIV settings on the BPAP ventilator. Finally, we tested only one particular type of nebulizer. We did not compare the vibrating-mesh nebulizer to jet nebulizer or a pressurized metered-dose inhaler/spacer. There are currently no approaches that allow placing these devices after the leak-port while still maintaining the nebulizer in a vertical position and minimizing unnecessary torque on the face mask. Improvements in device technologies and additional research are needed to determine whether changing these variables has any effect on patient comfort or aerosol delivery during simulated pediatric NIV. 


\section{Bronchodilator Delivery During Simulated Pediatric Noninvasive Ventilation}

\section{Conclusions}

Based on these findings, it would seem that clinicians should avoid placing the nebulizer back at the ventilator. The NIVO nebulizer represents an efficient lightweight nebulizer that can be easily integrated into a pediatric NIV mask without creating unnecessary torque and compromising the seal. If these bench data can translate into clinical practice, then the NIVO vibrating-mesh nebulizer may represent a novel approach for providing more timely and efficient drug delivery to pediatric patients receiving NIV for respiratory failure.

\section{REFERENCES}

1. Dohna-Schwake C, Stehling F, Tschiedel E, Wallot M, Mellies U. Non-invasive ventilation on a pediatric intensive care unit: feasibility, efficacy, and predictors of success. Pediatr Pulm 2011;46(11): 1114-1120.

2. Chatmongkolchart S, Schettino GPP, Dillman C, Kacmarek RM, Hess DR. In vitro evaluation of aerosol bronchodilator delivery during noninvasive positive pressure ventilation: effect of ventilator settings and nebulizer position. Crit Care Med 2002;30(11):25152519.

3. Winterhalter M, Bund M, Khaladj N, Hagl C, Simon A, Hoy L, et al. Aerosol delivery by an ultrasonic nebulizer during different mechanical ventilation settings in a lung model-a pilot study. Drug Des Devel Ther 2009;2(1):1-7.

4. Scala R. Noninvasive ventilation in severe acute asthma? still far from the truth (editorial). Respir Care 2010;55(5):630-637.

5. Schwartz AR, Kacmarek RM, Hess DR. Factors affecting oxygen delivery with bi-level positive airway pressure. Respir Care 2004; 49(3):270-275.

6. Scala R, Naldi M. Ventilators for noninvasive ventilation to treat acute respiratory failure. Respir Care 2008;53(8):1054-1080.

7. Hess DR, Pang JM, Camargo CA Jr. A survey of the use of noninvasive ventilation in academic emergency departments in the United States. Respir Care 2009;54(10):1306-1312.

8. Nava S, Karakurt S, Rampulla C, Braschi A, Fanfulla F. Salbutamol delivery during non-invasive mechanical ventilation in patients with chronic obstructive pulmonary disease: a randomized, controlled study. Intensive Care Med 2001;27(10):1627-1635.

9. Mukhopadhyay A, Dela Pena E, Wadden B, Procyshyn M, Keang Lim T. Effects of inhalational bronchodilator treatment during noninvasive ventilation in severe chronic obstructive pulmonary disease exacerbations. J Crit Care Med 2009;24(3):471-475.

10. Medoff BD. Invasive and noninvasive ventilation in patients with asthma. Respir Care 2008;53(8):740-748.

11. Lugogo NL, MacIntyre NR. Life-threatening asthma: pathophysiology and management. Respir Care 2008;53(6):726-735.

12. Hess DR. The mask for noninvasive ventilation: principles of design and effects on aerosol delivery. J Aerosol Med 2007;20(Suppl 1); S85-S91.
13. Yañez LJ, Yunge M, Emilfork M, Lapadula M, Alcántara A, Fernández $\mathrm{C}$, et al. A prospective, randomized, controlled trial of noninvasive ventilation in pediatric acute respiratory failure. Pediatr Crit Care 2008;9(5):484-489.

14. Akingbola OA, Simakajornboon N, Hadley EF Jr, Hopkins RL. Noninvasive positive-pressure ventilation in pediatric status asthmaticus. Pediatr Crit Care 2002;3(2):181-184.

15. Basnet S, Mander G, Andoh J, Klaska H, Verhulst S, Koirala J. Safety, efficacy, and tolerability of early initiation of noninvasive positive pressure ventilation in pediatric patients admitted with status asthmaticus: a pilot study. Pediatr Crit Care 2012;13(4):393-398.

16. Chin K, Uemoto S, Takahashi K, Egawa H, Kasahara M, Fujimoto $\mathrm{Y}$, et al. Noninvasive ventilation for pediatric patients including those under 1-year-old undergoing liver transplantation. Liver Transpl 2005;11(2):188-195

17. Dhand R. Aerosol therapy in patients receiving noninvasive positive pressure ventilation. J Aerosol Med Pulm Drug Deliv 2012;25(2): 63-78.

18. Kifle Y, Seng V, Davenport PW. Magnitude estimation of inspiratory resistive loads in children with life-threatening asthma. Am J Respir Crit Care Med 1997;156(5):1530-1535.

19. LaPrad AS, Lutchen KR. Respiratory impedance measurements for assessment of lung mechanics: focus on asthma. Respir Physiol Neurobiol 2008;163(1-3):64-73.

20. Ghazanfari T, Elhissi AM, Ding Z, Taylor KM. The influence of fluid physicochemical properties on vibrating-mesh nebulization. Int J Pharm 2007;339(1-2):103-111.

21. Ari A, Atalay OT, Harwood R, Sheard MM, Aljamhan EA, Fink JB. Influence of nebulizer type, position, and bias flow on aerosol drug delivery in simulated pediatric and adult lung models during mechanical ventilation. Respir Care 2010;55(7):845-851.

22. Fauroux B, Itti E, Pigeot J, Isabey D, Meignan M, Ferry G, et al. Optimization of aerosol deposition by pressure support in children with cystic fibrosis an experimental and clinical study. Am J Respir Crit Care Med 2000;162(6):2265-2271.

23. Abdelrahim ME, Plant $\mathrm{P}$, Chrystyn $\mathrm{H}$. In-vitro characterisation of the nebulised dose during non-invasive ventilation. J Pharm Pharmacol 2010;62(8):966-972.

24. Branconnier MP, Hess DR. Albuterol delivery during noninvasive ventilation. Respir Care 2005;50(12):1649-1653.

25. Calvert LD, Jackson JM, White JA, Barry PW, Kinnear WJ, O'Callaghan C. Enhanced delivery of nebulised salbutamol during non-invasive ventilation. J Pharm Pharmacol 2006;58(11):1553-1557.

26. Abdelrahim ME, Plant PK, Chrystyn H. The relative lung and systemic bioavailability of terbutaline following nebulisation in noninvasively ventilated patients. Int J Pharm 2011;420(2):313-318.

27. Fink JB. Aerosol delivery to ventilated infant and pediatric patients. Respir Care 2004;49(6):653-665.

28. DiBlasi RM, Coppolo DP, Nagel MW, Doyle CC, Avvakoumova VI, Ali RS, et al. A novel, versatile valved holding chamber for delivering inhaled medications to neonates and small children: laboratory simulation of delivery options. Respir Care 2010;55(4):419-426.

29. Ari A, Areabi H, Fink JB. Evaluation of aerosol generator devices at 3 locations in humidified and non-humidified circuits during adult mechanical ventilation. Respir Care 2010;55(7):837-844 